\title{
Evaluating Irreplaceable Loss : Some Implications for Insurance and Liability Rules
}

\author{
by Paul Fenn*
}

\section{Introduction}

There has been a longstanding debate amongst welfare economists over the importance of wealth effects in relation to the measurement of welfare change. Insofar as wealth or income effects imply an increase in a consumer's marginal valuation of expenditure on a good as his wealth increases, the outcome will be an indifference map in which the curves are not vertically parallel, and consequently the Hicksian measures of compensating and equivalent variation associated with the welfare benefit from the good will differ. This raises a number of questions in relation to the possibility of Scitovsky paradoxes, the validity of the Coase theorem and the measurement of consumer's surplus ${ }^{1}$. However, the practical importance of these questions has traditionally been played down, mainly due to the supposed empirical insignificance of wealth effects (Willig [1976]). Recent evidence which suggests a marked disparity between willingness to pay and compensation demanded measures in experimental data has therefore led to a number of alternative explanations being put forward ${ }^{2}$. It has been suggested that individuals evaluate gains and losses asymetrically relative to a particular reference point, implicitly giving rise to discontinuous utility functions (Knetsch [1984], Knetsch and Sinden [1985], Kahneman and Tversky [1979]). It has also been suggested that individuals are unwilling to disrupt an equilibrium state (Kelman [1979]). These explanations, relying as they do on psychological factors, represent a challenge to orthodox consumer theory.

Moreover, if we introduce uncertainty into the debate, the question becomes even more wide-ranging, given that there is a need to consider the consumer's valuation of insurance against any possible loss of the good, and the prevention of that loss occurring. The usual way of tackling these questions in recent years has been to utilise a framework of analysis in which utility functions are assumed to be state-dependent: that is, the loss of the

\footnotetext{
* I am grateful to Michael Jones-Lee, Goran Skogh, Jack Knetsch and participants at the joint EALE/Geneva Association seminar on Liability, Insurance and Safety Regulation, Geneva 7-8th April 1986. Any errors that remain are my own.

1. For a discussion of these and other implications of the valuation disparity, see Mishan (1967, 1971), Kelman (1979), Markovits (1980), Kennedy (1981), and Knetsch (1984).

2. The evidence has come from a number of studies, particularly with respect to environmental goods. See, for example, Rowe, d'Arge and Brookshire (1980), Meyer (1979), and Knetsch and Sinden (1985).
} 
benefits associated with a particular good will change the very nature of the consumer's utility function. This has enabled economists to demonstrate that rational risk-averse individuals will not fully insure against the loss of a good when that loss results in a reduction in the marginal utility of wealth (Zeckhauser [1973], Shavell [1978], Hirschleifer and Riley [1979]). This, of course, is a simple reformulation of the requirement that the consumer's indifference curves are not vertically parallel: a necessary and sufficient condition for a positive wealth effect. What is needed, and what is attempted in this paper, is a fuller integration of the treatment of wealth effects under conditions of certainty and uncertainty. It is inadequate simply to assume a given change in the marginal utility of wealth in order to explain observed phenomena; we need to know, within a framework of stable utility functions, what it is that causes such effects, and how they relate to real world problems. Section 2 of the paper presents an integrated treatment of wealth effects, following Cook and Graham [1977]. Section 3 examines the structure of the utility functions in relation to these effects and estimates their importance with given examples. Section 4 concludes with some implications of this analysis for the economic analysis of insurance, liability and safety.

\section{Evaluating Loss Under Conditions of Uncertainty}

In evaluating any particular loss from the consumer's perspective, the first thing to be established is whether or not a market exists for the good in question, through which the loss could be made good at the market price. If this is the case, then the loss of any such marketable good can be evaluated as simply equivalent to the purchase price.

The potential for ambiguity in the evaluation of loss only arises when the good, right or entitlement in question is not replaceable in the marketplace. Such irreplaceable losses can arise as a result of an exogenous alteration in the price of a good; the denial of access to a particular market; or the appropriation of a non-marketed good or entitlement. In each case the consumer's welfare loss may be monetized either by transferring to him an amount of wealth which exactly restores his original level of utility (the compensating variation); or by deducting from his wealth an amount which brings about a reduction in utility equivalent to the loss (the equivalent variation). We can illustrate the relationship between these two measures of welfare loss by means of a state preference diagram:

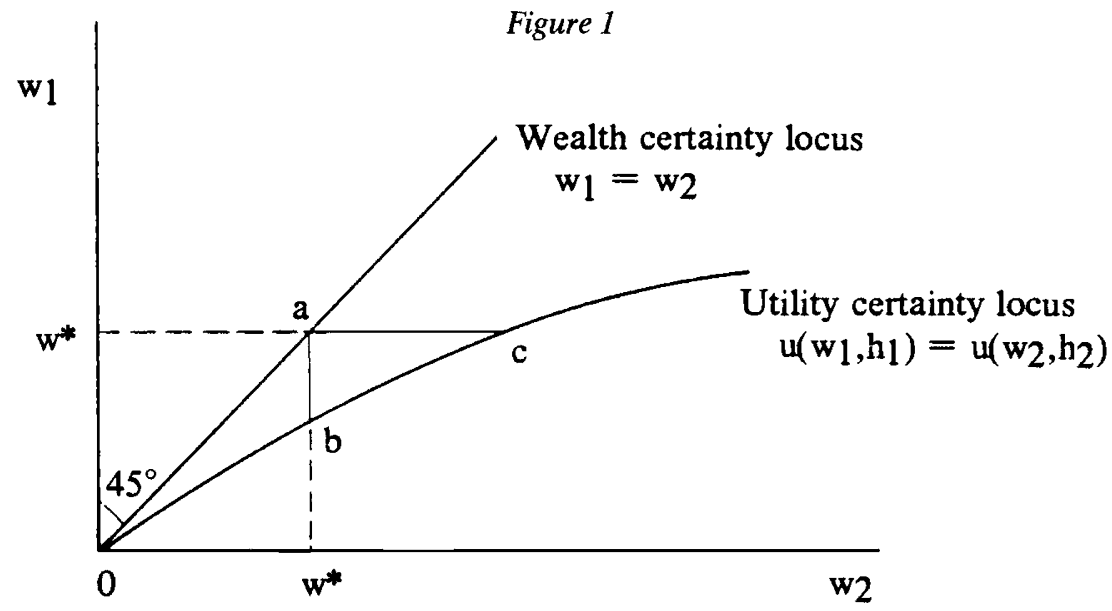


The axes $w_{1}$ and $w_{2}$ represent contingent claims to wealth given non-loss and loss respectively. The $45^{\circ}$ line represents the certainty locus for wealth, and the other line represents the certainty locus for utility, given a particular (irreplaceable) loss. That is, its represents those points at which $u\left(w_{1}, h_{l}\right)=u\left(w_{2}, h_{2}\right)$, where $u(w, h)$ is a utility function defined over wealth $(w)$ and an irreplaceable good $(h)$ which are assumed to be continuous real-valued variables such that $u_{w}, u_{h}>0$ and $u_{w w}, u_{h h}<0$. Since state 2 is defined as the loss state, it follows that $h_{2}<h_{1}$. The fact that $h$ is a normal good is shown by the shape of the utility certainty locus: as wealth increases, the consumer's valuation of the loss also increases. In fact, from a given initial wealth endowment $w^{*}$, the amount of wealth deduction equivalent to the loss is $a b$ the equivalent variation of the loss - and the amount of wealth supplementation needed to exactly compensate for the loss is $a c$ - the compensating variation. These measures will be different if the slope of the utility certainty locus is less than one : that is, if the marginal utility of wealth in the loss state is less than the marginal utility of wealth in the non-loss state ${ }^{3}$.

Diagram 1 shows that a disparity between the two measures of welfare loss is inevitable given a positive wealth effect: because the compensating variation implies that the consumer has to be compensated for the loss, whereas the equivalent variation implies that the consumer has to pay to avoid it, they are effectively based on different wealth/utility positions, and are therefore sensitive to wealth effects. However, given uncertainty over the likelihood of loss, the consumer may be tempted to transfer wealth between states using the insurance market, and this may bring the two measures closer together. Consider therefore diagram 2 , in which the possibility of fair insurance is represented by the budget line AB:

Figure 2

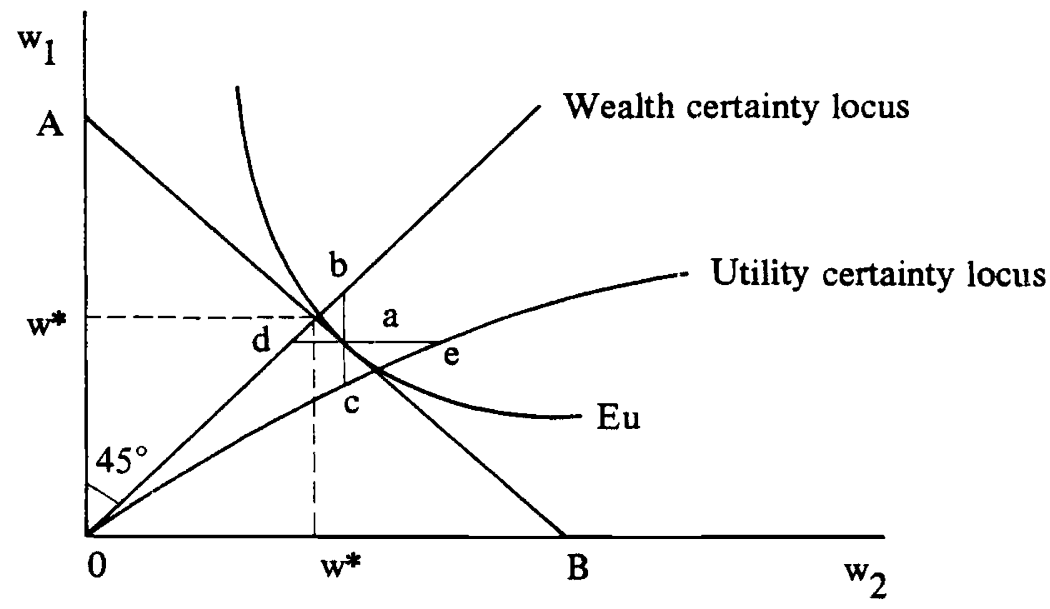

3. For a given loss, the equation for the utility certainty locus is $u\left(w_{1}, h_{l}\right)-u\left(w_{2}, h_{2}\right)=0$ Totally differentiating this and rearranging gives us :

$$
\left.\frac{d w_{1}}{d w_{2}}\right|_{u=\bar{u}}=\frac{u_{w}\left(w_{2}, h_{2}\right)}{u_{w}\left(w_{1}, h_{1}\right)}
$$


This shows how the consumer will, given fair insurance, move away from the wealth certainty locus by transferring wealth to the loss state. The optimal transfer is represented by $a$, where the consumer's expected utility is maximised, for a given probability of loss. In contingent claims space, this represents the point $\left(w^{*}-p i, w^{*}-p i+i\right)$, where $w^{*}$ is the original (certain) wealth endowment, $p i$ is the fair premium, and $i$ is the sum insured. Associated with this optimum are two further measures of value, $b c$ and $d e$, which represent the equivalent variation and compensating variation respectively ${ }^{4}$. The diagram has been drawn to show an underinsurance optimum. That this indeed the case with a normal irreplaceable good can be shown formally, given that optimal insurance requires that

$$
u_{w}\left(w^{*}-p i, h_{1}\right)=u_{w}\left(w^{*}-p i+i, h_{2}\right)
$$

and the normallity of $h$ implies that :

$$
u_{w}\left(w^{*}-p i+i, h_{2}\right)<u_{w}\left(w^{*}-p i+i-e, h_{1}\right)
$$

where $e$ is the equivalent variation of the loss, given insurance. Taking (1) and (2) together with the assumed concavity of $u$, it is clear that $e>i$ : optimal insurance is less than full insurance in this case.

Now Cook and Graham introduce one further measure of value, which they term the pure protection benefit from the avoidance of loss. That is, it is the value placed on avoiding a loss when fair transfers of wealth between states are possible. This value can be derived as the utility-maintaining wealth transfer associated with a small change in the probability of loss. The consumer's expected utility is given by:

$$
E U=p u\left(w^{*}-p i+i, h_{2}\right)+(1-p) u\left(w^{*}-p i, h_{l}\right)
$$

where $p i$ represents the fair premium given the probability of loss $p$. Totally differentiating this gives :

$$
\begin{aligned}
d E U=0 & =\left[u\left(w^{*}-p i+i, h_{2}\right)-p u_{w}\left(w^{*}-p i+i, h_{2}\right) . i\right. \\
& \left.-u\left(w^{*}-p i, h_{1}\right)-(1-p) u_{w}\left(w^{*}-p i, h_{1}\right) . i\right] d p \\
& +\left[p u_{w}\left(w^{*}-p i+i, h_{2}\right)+(1-p) u_{w}\left(w^{*}-p i, h_{1}\right)\right] d w
\end{aligned}
$$

Taking this together with the first order condition for optimal insurance given at (1) above; we get:

$$
\left.\frac{-d w}{d p}\right|_{d E U=0}=\frac{u\left(w^{*}-p i, h_{1}\right)-u\left(w^{*}-p i+i, h_{2}\right)}{u_{w}\left(w^{*}-p i, h_{l}\right)}+i
$$

4. That is, $b c$ represents the equivalent variation of the loss for an individual with certain wealth equal to $w^{*}-p i+i$; and $d e$ represents the compensating variation of the loss for an individual with certain wealth equal to $w^{*}-p i$. These measures are those used by Cook and Graham for the purpose of demonstrating upper and lower bounds to measures of value following optimal wealth transfers. They are, in fact, difficult to justify as common-sense measures of value as perceived by the insured: $a c$ and $a e$ are more appropriate in this respect. I am grateful to Michael Jones-Lee for this point. 
Hence the willingness to pay to avoid the insured loss of a normal irreplaceable good exceeds the insurance value of the good. Cook and Graham demonstrate further that this measure is bounded above and below by the compensating and equivalent variation measures associated with the insured loss, that is, by $b c$ and $d e$ in diagram 2.

In sum, the analysis of wealth effects under uncertainty leads to at least four potentially different measures of loss to the consumer: the compensation demanded in exchange for a certain insured loss; the willingness to pay to avoid a certain insured loss; the amount of insurance; and the willingness to pay for a marginal reduction in the probability of an insured loss. The disparity between these measures depends upon the extent of the wealth effect - the extent to which the marginal utility of wealth is affected by the loss, ceteris paribus. In the following section, we look into the characteristics of the irreplaceable good $h$ which determine the strength of these wealth effects.

\section{Substitutability and Separability}

In the previous section it was shown that wealth effects determined the slope of the utility certainty locus. Totally differentiating the equation for the latter gives us

$$
\frac{d w_{1}}{d w_{2}}=\frac{u_{w}\left(w_{2}, h_{2}\right)}{u_{w}\left(w_{1}, h_{1}\right)}
$$

Hence the slope depends on the relative effect of the loss in $h$ on the marginal utility of wealth. If we consider a consumer with an endowment of replaceable and irreplaceable goods, denoted $w$ and $h$ respectively, we can represent his consumption position simply as

$$
\begin{gathered}
\max u=u(w, h) \\
\text { subject to } h \leqslant \bar{h} \\
w \leqslant \bar{w}
\end{gathered}
$$

that is, the given endowment yields an attainable level of utility at which the following conditions hold:

$$
\begin{aligned}
& u_{w}=\lambda \\
& u_{h}=\gamma \\
& w=\bar{w} \\
& h=\bar{h}
\end{aligned}
$$

We wish to know what is the effect on the consumer should this endowment change. In particular, we are interested in the effect of a compensated reduction in the irreplaceable endowment, $\bar{h}$. This we can investigate using the usual method of comparative statics: totally differentiating the above conditions we get :

$$
\begin{aligned}
u_{w w} d w+u_{w h} d h & =d \lambda \\
u_{h w} d w+u_{h h} d h & =d \gamma \\
d w \quad & =d \bar{w} \\
d h & =d \bar{h}
\end{aligned}
$$

solving this system fo $d \lambda$ using Cramer's rule, we get :

$$
d \lambda=u_{w h} d \bar{h}-u_{w w} d \tilde{w}
$$


Where $\mathrm{d} \lambda$ can be interpreted as the change in the marginal utility of replaceable wealth. If we now assume that an exogenous loss in $h$ can be matched by a compensating amount of wealth in order to maintain a given level of utility, that amount will be given by:

$$
\left.d W\right|_{u=\bar{u}}=\underline{u}_{h} \cdot d \bar{h}
$$

and substituting this into (18) give us

$$
\left.\frac{d \lambda}{d h}\right|_{u=\bar{u}}=u_{w h}-\underline{u}_{h} \cdot u_{w w}
$$

This show how $\lambda$ changes along the compensated demand curve for $h$.

It follows that a necessary and sufficient condition for a positive wealth effect associated with the irreplaceable good is:

$$
u_{w h}-\frac{u_{h}}{u_{w}} \cdot u_{w w}>0
$$

Clearly if $w$ is a substitute for $h$, then $u_{w}=u_{h}$ and $u_{w w}=u_{w h}$ so that the wealth effect is zero, all measures of loss are equal, and full insurance is optimal. Where this is not the case, equation (21) tells us under what conditions the disparity in measures of value is likely to be greatest. The parameters determing the size of this effect are, in turn, the extent of nonseparability $\left(u_{w h}\right)$; the marginal rate of substitution between $h$ and other goods $\left(u_{h} / u_{w}\right)$; and the extent to which wealth is subject to diminishing marginal utility $\left(u_{w w}\right)^{5}$. Taken together, these factors emphasise the centrality of substitution and complementarity effects to the explanation of observed differences in measures of value. Where goods are lost without possibility of replacement, the extent to which imperfect substitutes must be consumed in order to compensate for the loss, and the effect this necessary shift in consumption has on marginal utility, are clearly factors capable of explaining observed ambiguity in evaluation. Moreover, where there is a high degree of non-separability between the irreplaceable good and other goods - that is, where the irreplaceable good is consumption-enhancing - then the effect of its loss on marginal utility is more pronounced.

It is in fact quite easy to think of goods which, characteristically enhance the enjoyment of life over a wide spectrum of consumption activities, and which, when lost, are not replaceable by very close substitutes. Clearly, good health is an asset which closely fits this description: any reduction in our state of health through illness or injury also has the effect of reducing the scope of our everyday activities. Moreover, as any disabled individual will testify, there are few good substitutes for the functional capabilities of the human body. A second class of goods which fits the description might be termed environmental assets: those amenities which, once destroyed, can never be recovered, and which are a necessary

${ }^{5}$ Alternatively, we could restate the condition for a positive wealth effect as:

$$
\frac{u_{w h}}{u_{h}}-\underline{u}_{w w}>0
$$

That is, the degree of financial risk aversion must exceed the degree of risk-aversion with respect to $h$. 
adjunct to the enjoyment of a range of leisure activities. Other goods may be consumptionenhancing, but easily replaceable - a car might fit into this category - in which case we would expect little disparity in measures of loss. On the other hand some goods may be unique, but highly specific in value - such as a family heirloom, for example. Here we would expect a disparity in measures of loss, but this would be entirely due to the impossibility of substitution; complementarity effects would not be relevant.

Cook and Graham present in an Appendix examples of utility functions for which they calculate the compensating and equivalent variations of an irreplaceable loss, together with the optimum insurance value. However, they make no attempt to explain how the structure of the utility function determines the nature of the wealth effect. For the purpose of this paper, we can specify utility functions in both separable and non-separable forms, and with varying degrees of concavity. Table 1 shows five such functions, giving values for the equivalent variation, compensating variation and optimal insurance associated with a given loss of an irreplaceable good, from $h_{1}$ to $h_{2}$.

Table 1

\begin{tabular}{|c|c|c|c|c|c|}
\hline Utility Function & $\mathbf{u}_{\mathrm{ww}}$ & $\mathrm{u}_{\mathrm{wh}}$ & EV & $\mathrm{CV}$ & $\mathrm{i}$ \\
\hline 1. $w+h$ & 0 & 0 & $\mathbf{h}_{1}-\mathbf{h}_{2}$ & $\mathbf{h}_{1}-\mathbf{h}_{2}$ & 0 \\
\hline 2. wh & 0 & 1 & $\frac{w-w h_{2}}{h_{1}}$ & $\frac{w_{h}}{h_{2}}-w$ & $\frac{-w}{1-p}$ \\
\hline 3. $1 \mathrm{n}(w+h)$ & $\frac{-1}{(w+h)^{2}}$ & $\frac{-1}{(w+h)^{2}}$ & $\mathbf{h}_{1}-\mathbf{h}_{2}$ & $\mathbf{h}_{1}-\mathbf{h}_{2}$ & $\mathbf{h}_{1}-\mathbf{h}_{2}$ \\
\hline 4. $1 \mathrm{nw}+1 \mathrm{nh}$ & $\frac{-1}{w^{2}}$ & 0 & $\frac{w-w h_{2}}{h_{1}}$ & ${\frac{w h_{1}}{h_{2}}-w}^{-w}$ & 0 \\
\hline 5. h. 1nw & $\frac{-\mathbf{h}}{\mathbf{w}^{2}}$ & $\frac{1}{w}$ & $\mathrm{w}-\mathrm{w}^{\mathrm{h} 2} / \mathrm{h} 1$ & $\mathrm{w}^{\mathrm{h} 1 / \mathrm{h} 2-\mathrm{w}}$ & $\frac{\underline{w}\left(h_{2}-h_{1}\right)}{h_{1}}$ \\
\hline
\end{tabular}

Cases 1 and 3 represent functions in which wealth is a perfect substitute for the irreplaceable good, hence there is no difference between CV and EV. However, in case 1, the consumer is risk neutral and consequently does not insure against the loss, whereas in case 3 , the consumer is risk averse and therefore insures against the wealth equivalent of the loss $\left(h_{1}\right.$ $h_{2}$ ). Cases 2 and 5 represent functions in which there is a relatively high degree of complementarity between the irreplaceable good and wealth, so that the consumer actually prefers to bet against the loss rather than insure. Moreover in both cases there is a disparity between $\mathrm{EV}$ and $\mathrm{CV}$, which is particularly pronounced in case 5 because of the conjunction of non-separability and concavity effects. Case 4 shows the effect of concavity alone, which 
by itself may produce a disparity in measures of loss due to imperfect substitution possibilities. By placing nominal values on $w, h_{1}$ and $h_{2}$ of 100,2 and 1 respectively we can get some idea of the potential for disparity. In cases 2 and 4 the $\mathrm{CV}$ is twice the $\mathrm{EV}$, and in case 5 it is no less than 110 times the EV! Clearly the latter result stems from an unrealistically high degree of complementarity between $w$ and $h$, but it does serve to make the point that certain types of irreplaceable asset might be expected to show considerable disparity in evaluation. Furthermore, the fact that a significant difference between the measures is observed in case 4 , where there are no complementarity effects, illustrates the fact that even quite "ordinary" goods may give rise to this phenomenon, providing that they are not replaceable in a given context.

\section{Summary and Implications}

This paper has briefly presented an analysis of the disparity in measures of loss, relying only on orthodox consumer theory for the argument. The paper has reviewed the contribution of Cook and Graham, who integrated the treatment of wealth effects under conditions of certainty and uncertainty, thereby allowing a unified approach to valuation and insurance questions. Under this approach, the existence of positive wealth effects in conjunction with irreplaceability creates a disparity in measures of value and an underinsurance optimum. This paper has extended the analysis by decomposing wealth effects to point up the importance of complementarity and substitutability characteristics. This implies not only that there are certain classes of irreplaceable asset such as health and environmental goods for which we would expect a sizeable disparity due to their pervasive benefits, but also that irreplaceable goods with relatively restrictive applications may yield significant disparities if there are no close substitutes available. The size of the wealth effect may depend on the existence of constraints to substitution, so that experimentally generated disparities in loss measures may in fact be specific to the context of the experiment. In Knetsch and Sinden's study, for example, individuals were asked to evaluate a mildly entertaining gamble with a low expected value. The fact that the differences between EV and CV were statistically significant may simply say something about the availability of alternative entertainment at that time and at that place. Moreover, the discovery of significant disparities for such goods is not necessarily inconsistent with the conventional wisdom that observed wealth effects are low: this view generally stems from evidence relating to price changes where goods are replaceable in the marketplace. In sum, it its possible to explain and predict significant evaluation ambiguity without recourse to psychological anomalies.

The importance of this finding stems from the fact that many of the property rights which are the subject or liability rules and risk-sharing agreements have the characteristics of irreplaceability, non-substitutability and/or complementarity which lead to the valuation problems outlined in this paper. As far a contractual liability is concerned, Rea [1982] has shown that where breach of contract involves the irreplaceable loss of a normal good, no single damage award will be capable of achieving both efficient breach and efficient insurance against the loss. Moreover, it is also true that a risk averse buyer will not fully insure against a price rise in a replaceable normal good, because the resulting shift in his optimal consumption bundle (with a smaller amount of the good whose price has risen) will reduce his marginal utility of wealth. For most goods, therefore, a breach of contract which could be mitigated through a replacement or the purchase of a perfect substitute at a higher price 
should result in a damage award below the cost of mitigation for efficient insurance. However, such an award would not ensure efficient breach. To add further complications, the damage award typically made by the courts in such cases would be the cost of complete substitution of the originally contracted-for quantity at the new price (Fenn [1981]). This is clearly higher than necessary for efficient breach, as well as being higher than necessary for efficient insurance. While the significance of these problems does of course depend on the strength of wealth effects, it nevertheless seems to be the case that damage awards reflecting expectation loss are unlikely to achieve simultaneous efficiency in both insurance and breach.

These problems are compounded in the case of liability under tort law where personal injury loss is concerned. In this case the non-separability effects could dominate, causing a marked divergence between compensation demanded and willingness-to-pay measures of loss. This divergence would remain even if fair insurance against personal injury loss were available, because it would not be optimal for a financially risk averse individual to fully insure. Moreover, it has been established that, in these circumstances, the measure of loss which is relevant for risk reduction is less than the fully compensating transfer: hence there can be no single damage award which will be capable of achieving efficient deterrence and full (ex post) compensation.

Finally, in the case of environmental or health entitlements which may be at stake in the regulatory process governing health, safety, land use or pollution matters, the question arises as to what should be the appropriate basis for aggregating costs and benefits resulting from policy changes. The orthodox answer to this question has typically been to evaluate policy on the basis of aggregated compensating variations : the policy is endorsed if the gainers can compensate the losers and remain better off. It has been suggested however, that the alternative criterion of aggregated equivalent variations might be more appropriate, so that policies would be endorsed only if the losers were unable to "buy out" the gainers. Markovits [1980] has argued that this criterion is preferable when it is clear that any supposed compensation to losers is purely hypothetical, in which case it is more appropriate to evaluate costs and benefits in relation to current (non-hypothetical) wealth positions. Whatever the merits in this argument, it would certainly seem to be the case that the chosen method of aggregation might affect the policy decision, given that there could be substantial differences between the two measures of value. However, this is only true for policy decisions relating to discrete changes in entitlements. Where a regulatory agency is concerned with policies designed to marginally affect the risk of harm, there will be an unambiguous measure of value represented by equation 4 ) above - the pure protection benefit given the possibility of fair transfers of wealth ${ }^{6}$. Again, for the kinds of harm we are contemplating here, this measure of value will exceed the insurance value but will be below the amount awarded by the courts in full compensation. This raises interesting issues with respect to the interaction between social insurance, safety regulation and liability. While these issues are beyond the scope of this paper, there would seem to be a case for a closer consideration of wealth effects and the characteristics of non-substitutability and non-separability which give rise to them.

6. This is analagous to the "value of life" measurements derived from behavioural responses to small changes in risk. As such, it is open to similar methodological reservations as those expressed by Broome (1978). 


\section{REFERENCES}

BROOME, J. (1978) “Trying to Value a Life" Journal of Public Economics.

COOK, P.J. and GRAHAM, D.A.(1977) "The Demand for Insurance and Protection: the Case of Irreplaceable Commodities", 91 Q.J. Econ. 143.

FENN, P.T. (1981). "Mitigation and the Correct Measure of Damage". International Review of Law and Economics 1, 223-226.

HIRSHLEIFER, J. and RILEY, J.G. (1979) "The Analytics of Uncertainty and Information - An Expository Survey", $17 \mathrm{~J}$. Econ. Lit. 1375.

KAHNEMAN, D. and TVERSKY, A. (1979) "Prospect Theory: An Analysis of Decision Under Risk" Econometrica 47, 263.

KELMAN, M. (1979) "Consumption Theory, Production Theory and Ideology in the Coase Theorem" Southern California Law Review 52(3) 669-698.

KENNEDY, D. (1981) “Cost-Benefit Analysis of Entitlement Problems: A Critique”, Stranford Law Review 33, 387-445.

KNETSCH, J.L. (1984) "Legal Rules and the Basis for Evaluating Economic Losses", International Review of Law and Economics 4(1) 5-14.

KNETSCH, J.L. and SINDEN, J.A. (1985) "Willingness to Pay and Compensation Demanded: Experimental Evidence of an Unexpected Disparity in Measures of Value", Quarterly Journal of Economics.

MARKOVITS, R. (1980) "Legal Analysis and the Economic Analysis of Allocative Efficiency" Hofstra Law review 8, 859-72.

MEYER, P.A. (1979) "Publicly Vested Values for Fish and Wildlife: Criteria in Economic Welfare and Interface with the Law" Land Economics 44, 223.

MISHAN, E.J. (1967) "Pareto Optimality and the Law" Oxford Economic Papers 19(3) 247-87.

MISHAN, E.J. (1971) “The Post-War Literature on Externalities: An Interpretive Essay” Journal of Economic Literature 9,1.

REA, S.A. (1982) "Nonpecuniary Loss and Breach of Contract”, $11 \mathrm{~J}$. Legal Studies 35.

ROWE, R.D., d'ARGE, R.C., and BROOKSHIRE, D.S. (1980) “An Experiment on the Economic Values of Visibility" Journal of Environmental Economics and Management 7,1.

SHAVELL, S. (1978) "Theoretical Issues in Medical Malpractice" in The Economics of Medical Malpractice (S. Rottenberg, ed.).

WILlIG, R.D. (1976) “Consumer's Surplus Without Apology” American Economic Review 66, 589.

ZECKHAUSER, R.J. (1973) “Coverage for Catastrophic Illness”, 21 Public Policy 149. 